\title{
Onion Trait Heritability and Response from Selection
}

\author{
Christopher S. Cramer ${ }^{1}$ \\ Department of Plant and Environmental Sciences, Box 30003, MSC 3Q, New Mexico State University, \\ Las Cruces, NM 88003-8003
}

\begin{abstract}
AdDitional INDEX words. Allium cepa, bolting, fusarium basal rot, pink root, single centers
Abstract. Realized heritability estimates of bolting percentage, pink root and fusarium basal rot severities and incidences, and percentage of single-centered bulbs were estimated for half-sib families of an intermediate-day, openpollinated onion (Allium cepa L.) population using selection response analysis. Half-sib families were selected based upon an index that equally weighted bolting percentage, pink root and fusarium basal rot severities and incidences, percentage of single-centered bulbs, and bulb quality. Families were subjected to one cycle of half-sib family recurrent selection. Pink root and fusarium basal rot severity was reduced by $17 \%$ and $7 \%$, respectively, with realized heritability estimates of 1.28 and $\mathbf{0 . 6 5}$, respectively. More progress for pink root severity was made than was selected. Disease incidence was reduced by $18 \%$ and $12 \%$, respectively, with heritability estimates of 0.65 and 0.60 , respectively. Very little progress was made for the percentage of single-centered bulbs and this was reflected in a heritability estimate of 0.17. Selection based upon multiple characters at the same time may reduce the effectiveness of making improvements in a single trait. However even with low to moderate heritability, improvements were made, and suggest that further improvements can be made through selection.
\end{abstract}

In the United States, onions are one of the top fresh market vegetables in terms of acreage, yield, and value (U.S. Department of Agriculture, 2006). In addition, onion consumption continues to grow at a steady rate. New Mexico has a long history of onion production and currently ranks as one of the top six onion producing states. Commonly, short- and intermediate-day onion cultivars are grown in New Mexico with autumn and winter plantings for early summer harvests. With autumn-sown onion cultivars, premature seedstalk formation or bolting can occur and, depending upon the extent, can reduce drastically onion yields. Bolting occurs when a plant has reached a certain sheath diameter and is exposed to a cold stimulus for a period of time. When both factors are ideal, the vegetative apical meristem will differentiate into a reproductive meristem and an axillary vegetative meristem. Plants that have bolted do not reliably form bulbs and cannot be stored, shipped, and sold. Onion cultivars differ in the sheath diameter size required to be receptive to a cold stimulus. Fall-seeded cultivars grown in New Mexico should be bolting resistant; otherwise, some yield reduction will be observed due to bolting.

Two soil-borne diseases, pink root and fusarium basal rot (FBR), are found ubiquitously in the United States and worldwide and can cause reductions in onion yields. Phoma terrestris (E.M. Hans.) Gorenz, J.C. Walker, \& R.H. Larson, causal organism of pink root, invades onion roots causing a purple discoloration and reduction in root mass and bulb size. Susceptible onion cultivars can have total root loss that results in small bulbs and low yields. Onion cultivars grown in New Mexico must be pink root resistant, or if susceptible be grown in fields not previously cultivated to onions; otherwise, yield reduction will be observed. Fusarium oxysporum Schlechtend.:Frf.sp.cepae (H.N.Hans.) W.C. Snyder

Received for publication 23 Feb. 2006. Accepted for publication 23 June 2006. This research was funded in part by the NMSU Agricultural Experiment Station and the New Mexico Dry Onion Commission. The author gratefully acknowledges technical assistance of Joe N. Corgan and Jose Luis Mendoza.

${ }^{1}$ Associate Professor of Horticulture.
\& H.N. Hans, causal organism of FBR, invades the basal plate of onion plants causing discoloration, tissue degradation, and eventual death of the plant. Chemical control is expensive and the most economical means of control are crop rotation and resistant cultivars. Crop rotation is becoming difficult to accomplish in south central New Mexico because rotation land is becoming scarce. Currently, FBR-resistant, short- and intermediate-day cultivars will need to be developed.

Many onion bulbs are processed into onion rings. The percentage of bulbs that produce a single growing point (single center) is an important trait when considering if an onion cultivar is suitable for onion ring processing. An onion cultivar that is used for onion ring processing must produce $85 \%$ or more bulbs with single centers. A cultivar that produces a high percentage of single-centered bulbs can be sold as fresh-market onions or as ring processing onions.

The heritability of a trait of interest must be known to develop efficient breeding strategies for trait improvement. Only a few studies have been conducted previously to determine onion trait heritability. Heritability of bolting percentage has been moderate to high (Cramer et al., 2001b; Villanueva-Mosqueda, 1996) while heritability of pink root and FBR incidence has been low to moderate (Cramer et al., 2001a; Villanueva-Mosqueda, 1996). Heritability of the percentage of single center bulbs also has been low (Wall et al., 1996). However, in our breeding program, we have been able to develop cultivars with a high level of bolting and pink root resistance and high percentage of single-centered bulbs using phenotypic recurrent selection. These traits would have been difficult to improve using phenotypic recurrent selection if the heritability of these traits had been low in the selected populations. The objectives of this study were to measure the response from selection using half-sib family recurrent selection; to determine realized heritability estimates for the traits measured; to determine to what extent further progress can be made in an improved population; and to determine the effectiveness of an index based selection scheme for trait improvement. 


\section{Materials and Methods}

GeNETIC MATERIaL. NMSU 97-12 is an intermediate-day, fallseeded, bolting-resistant, late-maturing, open-pollinated population that produces white-scaled, globe-shaped, hard bulbs that are high in soluble solids and the percentage of single centers. When tested in cultivar trials at Las Cruces, N.M., it matured from 13 to 22 June when fall-seeded and produced an average of $65 \%$ to $74 \%$ bulbs with single centers (Cramer et al., 2000, 2001b). NMSU 97-12 also exhibits a high level of bolting and pink root resistance. Scape incidence ranged from $2 \%$ to $11 \%$, while pink root severity ranged from 2.2 to 4.0 on a scale of $1-9$ with higher rated bulbs possessing more pink root symptoms (Cramer et al., 2000, 2001b). NMSU 97-12 originated from four individual paired crosses between a bolting resistant selection of 'Ben Shemen' and 'Southport White Globe.'These two cultivars are open-pollinated populations that are variable for many characters. The resulting progeny from those crosses were massed together and the resulting population was subjected to nine cycles of phenotypic recurrent selection prior to the development of NMSU 97-12. After two more cycles of selection, NMSU 97-12 was released as 'NuMex Solano' (Cramer and Corgan, 2003).

Seeds of NMSU 97-12 were planted on 1 Sept. 1997, that is, 3 to 4 weeks earlier than the earliest recommended planting date for fall-planted onions in southern New Mexico. This early planting date was used to ensure a high percentage of plants with seedstalks and to allow for the selection of bolting resistant plants. Two equally-spaced rows were seeded into standard vegetable beds $1 \mathrm{~m}$ wide (center to center). Approximately 10-12 weeks after seeding, plants were thinned to $10 \mathrm{~cm}$ between plants within the row. Plants were irrigated with subsurface drip irrigation that had $20 \mathrm{~cm}$ between emitters that were placed $10 \mathrm{~cm}$ below the soil surface. Plants were grown using standard cultural practices for onion production in southern New Mexico (Corgan et al., 2000). The fields used for selection are severely infested with $P$. terrestris and $F$. oxysporum f.sp. cepae. The high levels of these organisms has allowed previously for the selection of plants that are resistant to pink root and/or FBR. Plants were fertilized through the drip lines with $30 \mathrm{mg} \cdot \mathrm{kg}^{-1}$ of urea and ammonium nitrate $32 \mathrm{~N}-\mathrm{OP}-0 \mathrm{~K}$ (URAN 32) as needed. During the growth of the crop, permethrin (Karate; Syngenta Crop Protection, Inc., Greensboro, N.C.) was applied at a rate of $42.7 \mathrm{~mL} \cdot \mathrm{ha}^{-1}$ a.i. to control onion thrips (Thrips tabaci Lindeman) populations.

Bulbs were harvested when $80 \%$ of the plant tops were down on 30 June 1998. Only bulbs that had not produced a seedstalk were selected. Bulbs were evaluated for pink root and FBR resistance, bulb shape, bulb size, shape uniformity, bulb maturity, maturity uniformity, bulb color, dry outer scale characteristics (number of layers, thickness, retention, adherence), and bulb firmness. Selection for pink root and FBR resistance was achieved by selecting bulbs that had no visible symptoms of either disease. Bulbs that were the same size and possessed a round, globe shape were selected. Selection for outer bulb scale color was based on bulbs that possessed clear white scales without any greening or brown discoloration. Selection for bulb shape and color was based on visual subjective observation. Selection for bulb firmness was based on a subjective evaluation of the amount of bulb scale resistance when bulbs were hand squeezed. Selection for bulb maturity was based on bulbs that matured by the third week of June. A total of 932 bulbs were selected from the field. Bulbs were stored at ambient atmospheric conditions for 2.5 months. During storage, bulbs were graded to remove bulbs that were lost to bacterial infections or FBR infections. A total of 326 bulbs remained after storage. Once bulbs were removed from storage, they were cut transversely at the vertical center of the bulbs to select bulbs with a single growing point. Bulbs with a single growing point or multiple growing points within $1.3 \mathrm{~cm}$ from the center of the bulb were selected. After selection, 181 bulbs remained. These bulbs were placed in the ground in another field for seed production. At this time, the breeding line was given a new number, NMSU 99-99.

Bulbs were spaced $\approx 30 \mathrm{~cm}$ apart in a single row for a total length of $18 \mathrm{~m}$. A total of three beds were planted in this fashion. In Apr. 1999, seedstalks arising from bulbs were visible. A metal frame structure $(1.5 \mathrm{~m}$ high $\times 3 \mathrm{~m}$ wide $\times 18 \mathrm{~m}$ long $)$ was constructed and placed over all bulbs. A white polyester fabric was placed over the metal frame and sealed at the soil surface with soil. Once $10 \%$ of the total umbels were open, three hives of honeybees were introduced into the cage structure and they were allowed to move pollen among all umbels. After 1 month, all honeybees were removed from the cage since all flowers had opened and capsule formation had begun. In mid-July 1999, umbels were harvested from each plant and given a unique number that constituted a separate half-sib family. For each family, the entire population is serving as the male parent while each family has separate female parents. A total of 181 half-sib families were generated and seed weight was measured for each family. Only 96 half-sib families produced sufficient seed for replicated field evaluation. Remnant seed from these 96 families plus the seed from the 85 unused half-sib families was recombined to reconstitute the original population, NMSU 99-99.

Field EXPERIMENTAL DESIGN. Half-sib families and NMSU 97-12 were planted on 21 Sept. 1999 at the Fabian Garcia Science Center in Las Cruces, N.M. Four replications were planted for each family and the unselected parent population, and a plot was $2.5 \mathrm{~m}$ in length and $0.6 \mathrm{~m}$ in width. Two equally-spaced rows were seeded into standard vegetable beds $1 \mathrm{~m}$ wide (center to center). Plots were separated by alleys that were $0.6 \mathrm{~m}$ in length. On 9 Nov. 1999, plants were thinned to $10 \mathrm{~cm}$ between plants within row. Plants were grown using cultural practices described previously.

When $80 \%$ of the plants within the plot were mature, the presence of seedstalks was recorded for the first 40 plants in the plot. The root systems of 30 randomly-selected bulbs per plot were rated for pink root severity using a subjective rating of 1 (no pink roots) to 9 (heavily infected roots). The basal plates of the same 30 bulbs were cut transversely and the severity of FBR was rated using a subjective rating of 1 (no diseased tissue) to 9 (70\% or more diseased tissue). An average pink root rating and FBR rating were calculated. The percentage of diseased bulbs (either pink root or FBR) was calculated using the rated bulbs. For each plot, all bulbs were evaluated for quality that included shape, size, maturity, firmness, number of scale layers, and dry outer scale thickness, adherence, retention, and color. The desired bulb characteristics were round globe shape, large bulbs, uniform bulb maturity, hard bulb firmness, and multiple dry outer scale layers, that were thin and remained on the bulb. The highest quality bulbs were selected for each plot, and retained. These bulbs were removed from the plot, sacked, and stored. Selection for high quality bulbs mimicked the phenotypic recurrent selection process used in our breeding program to select superior individuals. Of the bulbs that remained at the plot, 30 bulbs per plot were cut transversely at the vertical center of the bulb. The percentage of bulbs with single growing points was determined by counting 
the number of bulbs with a single growing point (single center) or multiple growing points located within $13 \mathrm{~mm}$ from the center of the bulb and dividing by 30 .

Selection of half-sib families used a weighted index that considered bolting, pink root, FBR, percentage of single centers, and bulb quality characteristics for each half-sib family. Each trait was weighted equally in the index. The weighted index was calculated for each plot as $0.2[(100$ - bolting percentage $) / 10]+$ $0.2(10$ - average pink root $)+0.2(10$ - average FBR $)+0.2($ percentage single centers/10) + 0.2(number of bulbs selected/2.4). The average pink root and FBR values were calculated as $=[(10$ - rating $)+(100$ - incidence $) / 10] / 2$ ] for each respective disease. An average weighted index was calculated for each half-sib family from the four replications. The 10 half-sib families that had the highest weighted index values were selected and the 256 selected bulbs from these families were combined to form a new population, NMSU 01-99. The average weighted index of the selected bulbs was 7.2, which was greater than the index values of overall population, 6.7 and the previous generation, 6.6. Bulbs were placed in a crossing cage and seed was produced in a manner described previously. A selection differential was calculated for each trait as the difference in the trait mean of the selected individuals minus the mean of the entire population.

RESPONSE FROM SELECTION. Seed from NMSU 01-99 and NMSU 99-99 were planted on 10 Sept. 2001 and 13 Sept. 2002 at the Fabian Garcia Science Center. Four replications were planted for each population and plot size was the same as described previously. Plants were grown using cultural practices described previously. At harvest, plots were evaluated for bolting percentage, pink root and FBR severity and incidence, bulb quality, and the percentage of single-centered bulbs. The evaluation procedure was the same as the procedure described for the field experimental design. The only change was that 25 bulbs instead of 30 bulbs were used for calculating pink root and FBR severity and incidence and the percentage of single-centered bulbs. The weight index, described previously, was calculated for each population from the four replications.

The means for each trait over four replications were calculated for each breeding lines and for the sum of line within each group using the Proc Means statement of the SAS statistical software (SAS Institute, Cary, N.C.). Differences between lines were calculated for each trait using the Proc GLM statement of SAS. In addition, a protected Fisher's least significant difference (LSD) mean separation test was calculated at a probability level of 5\% for each trait using SAS. A selection response was calculated for each trait as the mean of the NMSU 01-99 population minus the mean of the NMSU 99-99 population. The realized heritability of each trait was calculated as the selection response divided by the selection differential. One cycle of half-sib family recurrent selection was used to calculate the response to selection.

\section{Results and Discussion}

Bolting PERCENTAGe. The bolting percentage of NMSU 01-99, the population derived from the best selection of 99-99, was $3.44 \%$, while the bolting percentage of NMSU 99-99 was $1.71 \%$. This results in a selection response of 1.73 that is in the opposite direction of the selection differential and generates a realized heritability estimate of zero (Table 1). There are several explanations for the lack of progress in this population. The population, NMSU 99-99, has been selected for reduced bolting percentage for a number of generations (Cramer and Corgan,
2003), and much of the variation for bolting percentage has been reduced. With very little variation in bolting percentage, identifying bolting susceptible individuals would be difficult. In addition, when bolting percentages are very low, further reduction in bolting would be difficult. The bolting percentages currently observed would be commercially acceptable. If greater levels of bolting resistance were desired, high bolting percentages might be achieved through earlier seeding dates. Earlier seeding dates would produce larger plants (Cramer, 2003) and a higher percentage of plants would reach the critical plant size required to be receptive to a cold stimulus and subsequently form a seed stalk. Half-sib families in this study were seeded on 21 Sept., and selections were made the following year. This seeding date is 3 weeks later than the seeding used in developing bolting-resistant, open-pollinated, breeding lines in our breeding program. If the half-sib families had been seeded earlier, high bolting percentages might have occurred and more progress might have been achieved. However, with higher bolting percentages, the number of bulbs to evaluate for disease resistance, percentage of single centers, and bulb quality decreases and the progress made for those traits may also decrease.

Pink Root SeVerity AND InCIDENCE. Some progress was made for reducing pink root severity and incidence in the new population, NMSU 01-99, as compared to the previous population, NMSU 99-99. After selection, pink root severity decreased $17 \%$ from 2.13 to 1.76 while incidence decreased $18 \%$ from $57.6 \%$ to $47.0 \%$ (Table 1). With a selection differential of -0.29 and a selection response of -0.37 , the realized heritability estimate for pink root severity was 1.28 for the NMSU 01-99 population (Table 1). An estimate greater than one was generated because more progress was achieved than was predicted from the selection differential. With a selection differential of $16.2 \%$ and a selection response of $10.6 \%$, the realized heritability estimate for incidence was 0.65 . In other populations in our breeding program, heritability of pink root incidence has been low to moderate (Cramer et al., 2001a; Villanueva-Mosqueda, 1996). The levels of pink root severity and incidence exhibited by the NMSU 01-99 population would be commercially acceptable and also would be lower than some commercial cultivars (Cramer and Muhyi, 2002). In addition, low levels of pink root can be observed at harvest time with no apparent impact on yield. Based on the results of this study, further gains in reducing pink root incidence are possible in this population; however, these gains may not be needed.

FUSARIUM BASAL ROT SEVERITY AND INCIDENCE. In using half-sib family recurrent selection to improve the NMSU99-99 population, FBR severity improved by $7 \%$ from 2.01 to 1.86 for a realized heritability of 0.65 (Table 1 ). Some progress was made for reducing incidence in the new population, NMSU 01-99, as compared to the previous population, NMSU 99-99. After selection, FBR incidence decreased $12 \%$ from $20.95 \%$ to $18.5 \%$ (Table 1 ). With a selection differential of $4.05 \%$ and a selection response of $2.45 \%$, the realized heritability for FBR incidence was 0.60 for the NMSU 01-99 population (Table 1). In other populations in our breeding program, heritability of FBR incidence has been low to moderate (Cramer et al., 2001a; Villanueva-Mosqueda, 1996). From these results, progress in reducing the number of bulbs that are FBR susceptible may be easier to accomplish than reducing the severity of FBR symptoms on those bulbs that are FBR-susceptible. This conclusion would be supported by observations made by our breeding program that once a bulb has become infected with FBR, the disease will continue to progress until the entire basal plate is comprised of diseased tissue (Cramer and Gutierrez, 2005). An 
Table 1. Trait performance of onion populations, NMSU 01-99 and NMSU 99-99 and selection differential (SD), response to selection (SR), and realized heritability $(\mathrm{RH})$ for measured traits when both populations were grown in Las Cruces, N.M.

\begin{tabular}{|c|c|c|c|c|c|c|c|c|}
\hline Populationz & $\begin{array}{c}\text { Seedstalk } \\
(\%)^{y}\end{array}$ & $\begin{array}{l}\text { Pink root } \\
\text { severity }\end{array}$ & $\begin{array}{c}\text { Pink root } \\
\text { incidence }(\%)^{\mathrm{w}}\end{array}$ & $\begin{array}{c}\text { FBR } \\
\text { severityv }\end{array}$ & $\begin{array}{c}\text { FBR } \\
\text { incidence }(\%)^{\mathrm{u}}\end{array}$ & $\begin{array}{c}\text { Single } \\
\text { centers }(\%)^{\mathrm{t}}\end{array}$ & $\begin{array}{c}\text { Bulbs } \\
\text { selected/plot }\end{array}$ & $\begin{array}{l}\text { Weighted } \\
\text { index }^{r}\end{array}$ \\
\hline NMSU 01-99 & 3.44 & 1.76 & 47.00 & 1.86 & 18.50 & 87.50 & 4.75 & 7.34 \\
\hline NMSU 99-99 & 1.71 & 2.13 & 57.55 & 2.01 & 20.95 & 87.04 & 2.00 & 6.79 \\
\hline \multicolumn{9}{|l|}{ Measure } \\
\hline SD & -0.31 & -0.29 & -16.18 & -0.23 & -4.05 & 2.69 & 2.55 & 0.52 \\
\hline SR & 1.73 & -0.37 & -10.55 & -0.15 & -2.45 & 0.46 & 2.75 & 0.55 \\
\hline RH & 0.00 & 1.28 & 0.65 & 0.65 & 0.60 & 0.17 & 1.08 & 1.06 \\
\hline
\end{tabular}

The two populations were not different from each other for all measured traits.

yThe percentage of seedstalks was determined at harvest and calculated by dividing the number of plants with seedstalks by the total number of plants per plot.

xRoot systems of 30 bulbs/plot were rated based on a scale of 1 (no infected roots) to 9 (completely infected roots).

wPercentage of bulbs with pink root.

${ }^{v}$ Cut basal plates of 30 bulbs/plot were rated for fusarium basal rot (FBR) based on a scale of 1 (no disease tissue) to 9 (70\% or more of basal plate decayed).

uPercentage of bulbs with fusarium basal rot (FBR).

The percentage of bulbs with single centers (single growing points) was determined by cutting 30 bulbs transversely at the vertical center and counting the number of bulbs with a single growing point (single center) or multiple growing points located within 13 mm from the center of the bulb and dividing by 30 .

sBulbs were selected at each plot based on bulb quality traits that included shape, size, maturity, firmness, number of scale layers, and dry outer scale thickness, adherence, retention, and color.

rSelection index $=0.2[(100-$ bolting percentage $) / 10]+0.2(10-$ average pink root $)+0.2(10$ - average FBR $)+0.2($ percentage single centers $/ 10)+0.2$ (number of bulbs selected/2.4). The average pink root and fusarium basal rot values were calculated as $=[(10-\mathrm{rating})$ $+(100-$ incidence $) / 10] / 2]$ for each respective disease.

evaluation strategy, that may make selection more effective and also result in more progress, would be to rate bulbs for FBR after they had been stored for 4 weeks rather than evaluating bulbs at harvest time. This additional period of time would allow for further disease development in bulbs expressing FBR symptoms and also disease development in those bulbs that are FBR-infected but not yet expressing symptoms. The bulbs used in this study were evaluated for FBR at harvest time. In other cultivars, we have observed an increase in FBR severity and incidence after bulbs have been stored for 4 weeks after harvest (Cramer and Gutierrez, 2005). Based on the results of this study, further gains in reducing FBR incidence are possible in this population. However, a selection based on a family structure may yield more progress than selection based on individual plants.

Percentage of Single-Centered bulbs. Very little progress was made for increasing the percentage of single-centered bulbs in the new population, NMSU 01-99, as compared to the previous population, NMSU 99-99. After selection, the percentage of single-centered bulbs increased $0.5 \%$ from $87.04 \%$ to $87.5 \%$ (Table 1). With a selection differential of $2.69 \%$ and a selection response of $0.46 \%$, the realized heritability for FBR incidence was 0.17 for the NMSU 01-99 population. The percentage of single-centered bulbs exhibited by the NMSU 01-99 population would be commercially acceptable; however, a higher percentage would be desirable. In other populations in our breeding program, heritability of single centers percentage has been high in one population (Cramer et al., 2001a) and low in other populations (Wall et al., 1996). We have developed some cultivars that express a higher percentage of single-centered bulbs than NMSU 01-99. Based upon the progress that our breeding program has made in increasing the percentage of single-centered bulbs in a population in a relatively short period of time, this trait most likely has a moderate to high heritability.

Bulb QuAliTy. As mentioned earlier, half-sib families were evaluated for their bulb quality and the bulbs with the best qual- ity were selected from each plot and each family. We were also interested if we could improve bulb quality with selection and increase the number of bulbs selected per plot. An average of 6.4 bulbs per plot were selected for the best selection as compared to 3.8 bulbs selected per plot for the overall population, NMSU 99-99 (data not shown). This selection resulted in a selection differential of 2.55 bulbs (Table 1). For the NMSU 01-99, an average of 4.75 bulbs were selected per plot as compared to 2.0 bulbs selected per plot for NMSU 99-99 (Table 1). This resulted in a selection response of 2.75 (Table 1). Since the selection response was greater than the selection differential, the realized heritability for the number of bulbs selected per plot was greater than one (1.08) (Table 1).

Selection index. As mentioned earlier, the best half-sib families were selected based upon an index that equally weighted bolting percentage, pink root and fusarium basal rot severities and incidences, percentage of single-centered bulbs, and bulb quality. Since this index was being used as the selection method, the realized heritability of this trait was determined to see if progress was made. The 10 best families had an average index value of 7.2 while the overall population had an average index value of 6.7 (data not shown). This selection resulted in a selection differential of 0.5 (Table 1). After selection and recombination, the weighted index increased $8 \%$ from 6.79 to 7.34 for the NMSU 01-99 population (Table 1). With a selection response of 0.55 , the realized heritability was 1.06 (Table 1 ). From these results, selection based on this index was quite effective in improving multiple traits at the same time. This selection index mimics actual applied breeding selection in which plants are selected based on their performance for multiple characters rather than for a single character.

Since the 10 half-sib families that comprised NMSU 01-99 were selected using an index that equally weighted six traits, the families that had the highest value for a single trait may not have been selected. When multiple traits are selected at the same 
time, the progress made in any trait may be less than if selection had been based on that trait solely. For example, if 10 half-sib families had been selected based on their bolting percentages solely, the progress may have been greater and the heritability estimates may be higher.

One shortcoming of realized heritability estimates is in the way that the components of the estimate are derived. The realized heritability estimate is calculated as the selection response divided by the selection differential. However, those two measures are often calculated from data collected from separate years and it would be very difficult to collect data for both measures in the same year. In this study, the selection differential was calculated from data collected in year 2000 while the selection response was calculated from data collected in years 2002 and 2003. Environmental differences from year to year could result in differences in bolting and disease incidences, percentage of single-centered bulbs, and bulb quality. These environmental differences could result in a lack of progress or excessive progress when a realized heritability estimate is calculated.

In conclusion, realized heritability estimates were variable from trait to trait. Progress was made for all traits except bolting percentage. The selection index used was effective for improving multiple traits at the same time. The traits measured in this study could be further improved in this population using some of the methods mentioned.

\section{Literature Cited}

Corgan, J.N., M.M. Wall, C.S. Cramer, T. Sammis, B. Lewis, and J. Schroeder. 2000. Bulb onion culture and management. N.M. Coop. Ext. Serv. Circ. 563.

Cramer, C.S. 2003. Performance of autumn-sown onion cultivars using four seeding dates. J. Amer. Soc. Hort. Sci. 128:472-478.

Cramer, C.S. and J.A. Gutierrez. 2005. Screening autumn-sown onion lines for fusarium basal rot resistance. HortScience 40:157-160.

Cramer, C.S. and J.N. Corgan. 2003. 'NuMex Solano'onion. HortScience 38:308-310.

Cramer, C.S. and R.I. Muhyi.2002. 2001-2002 fall planted onion cultivar trials at New Mexico State University, p. 23-33. In: G. Pelter (ed.). Proc. 2002 Natl. Onion Res. Conf., Pasco, Wash.

Cramer, C.S., J.N. Corgan, J.L. Mendoza, and M.M. Wall. 2000. 19981999 onion cultivar trials at New Mexico State University. N.M. Agr. Expt. Sta. Res. Rpt. 739.

Cramer, C.S., J.N. Corgan, J.L. Mendoza, and M.M. Wall. 2001a. Onion breeding research at New Mexico State University, p. 202-204. In: B. Randle (ed.). Proc. Alliums 2001. The 3 ${ }^{\text {rd }}$ Intl. Symp. on Edible Alliaceae. Athens, Ga.

Cramer, C.S., J.N. Corgan, J.L. Mendoza, and M.M. Wall. 2001b. 1999-2000 Onion cultivar trials at New Mexico State University. N.M. Agr. Expt. Sta. Tech. Rpt. 38.

U.S. Department of Agriculture. 2006. Vegetables. 2005 Summary. Vg 1-2 (06). U.S. Govt. Printing Office, Washington, D.C.

Villanueva-Mosqueda, E. 1996. Onion heritability for pink root resistance, fusarium basal rot resistance and bolting traits. MS Thesis, New Mexico State Univ., Las Cruces.

Wall, M.M.,A. Mohammad, and J.N. Corgan. 1996. Heritability estimates and response to selection for the pungency and single center traits in onion. Euphytica 87:133-139. 